\title{
CALCULATION METHOD OF LOAD CONDITIONS FOR PERFORMANCE TEST OF RAIL FASTENINGS OF A FLOATING SLAB TRACK
}

\author{
SHINGO TAMAGAWA \\ Department of Track Structures and Components, Railway Technical Research Institute, Japan
}

\begin{abstract}
This study aims to establish a calculation method of load conditions for a performance test of rail fastenings of a floating slab track. A floating slab track is a type of vibration-reducing tracks. It is composed of rails, rail fastenings and concrete slabs supported by elastic layers such as coil springs. Among these components, the design of rail fastenings is an important factor in determining the performance of the floating slab track. In the design of rail fastenings, the Japanese design standard for railway structures requires that the performance of rail fastenings should be checked by the static loading test at a laboratory. In the performance test, the test load is applied to the rail in consideration of the load dispersion by the track. In this study, an FEM model of the floating slab track is developed to estimate the dispersed forces. It also shows the calculation method of load conditions for a performance test of rail fastening of the floating slab track. Furthermore, the performance test of the rail fastening is performed.
\end{abstract}

Keywords: rail fastening, floating slab track, performance test, load condition, FEM.

\section{INTRODUCTION}

A floating slab track is a type of vibration-reducing tracks and is composed of rail, rail fastenings and concrete slabs supported by elastic layers such as coil springs (Fig. 1). Even among these components, the design of rail fastenings is an important factor in the determining the performance of the floating slab track. In the design of rail fastenings, the Japanese design standard for railway structures (RTRI [2]) requires that the performance of rail fastenings should be checked by the static loading test at a laboratory (hereafter, performance test). Fig. 2 shows examples of the test arrangement for a general rail fastenings. In the test, the test load is applied to the rail in consideration of the load dispersion by the track (Youichi [3]). The dispersed design load, namely vertical rail pressure, lateral rail pressure, and rail tilting moment should be applied to the rail with a single assembled rail fastening. Vertical and lateral rail pressures refer to the dispersed forces that act on a single assembled rail fastening when the wheel load and lateral load act on the track. Rail tilting moment refers to the moment by rail tilting that acts on a single assembled rail fastening and is defined around the central point of the rail bottom surface. These dispersed forces have been estimated using the practical solution based on the torsion theory (Yutaka [4], Takeshi et al. [5]). On the other hand, the author has developed the FEM model of a ballasted track or a general slab track to estimate the dispersed forces mentioned above and has proposed the calculation method of the load conditions for the performance test of rail fastenings based on the FEM results (Shingo et al. [6], Tadashi et al. [7]). However, the conventional FEM model cannot be applied to the floating slab track.

In this study, a FEM model of the floating slab track is developed to estimate the dispersed forces and the calculation method of load conditions for a performance test of rail fastening of the floating slab track is shown. Furthermore, the performance test of the rail fastening is performed. 


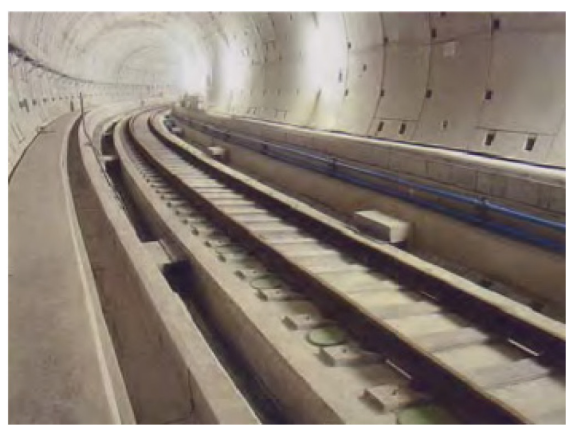

Figure 1: Floating slab track [1].

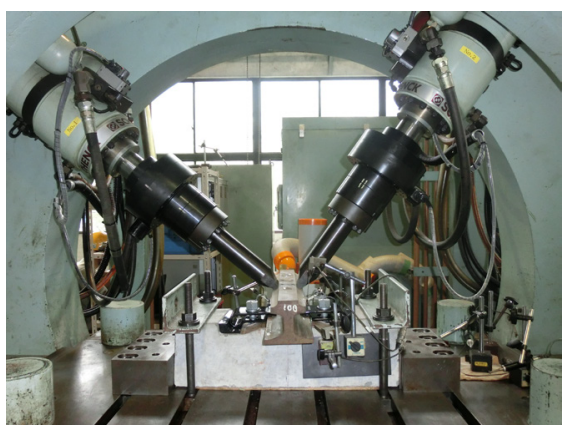

Figure 2: Performance test arrangement for rail fastenings.

\section{FEM MODEL OF A FLOATING SLAB TRACK}

\subsection{FEM model}

Fig. 3 shows the FEM model of a floating slab track. The FEM model is composed of solid elements, plate elements and spring elements. The rail is modelled by solid elements and is supported by 64 rail fastenings, which are spaced at $625 \mathrm{~mm}$ intervals. Two slabs are modelled by plate elements and are supported by 32 coil springs, which are spaced at $1,250 \mathrm{~mm}$ intervals. The rail clips composed of tip springs and lateral springs are modelled by non-linear elastic spring elements. The tie plates are modelled by plate elements. The springs under the rail and under the tie plates are modelled by the non-linear spring elements as well as the rail clips. The following are the constraining conditions of the respective elements.

- All elements: $v=0$ on the cross section to which loads are applied

- Slabs: $u=\theta_{y}=0$ on the side opposite to the rail

- Coil springs: $u=v=w=\theta_{x}=\theta_{y}=\theta_{z}=0$ on the side opposite to the slabs.

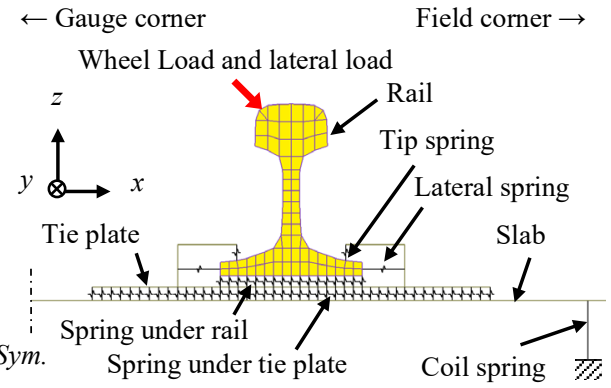

(a)

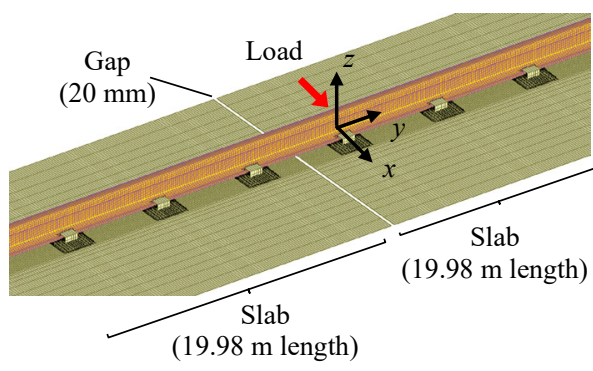

(b)

Figure 3: FEM model of a floating slab track. (a) Rail cross section; and (b) Longitudinal direction. 
Here, $u, v$, and $w$ indicates the displacement in $x, y$, and $z$ directions and $\theta_{x}, \theta_{y}$, and $\theta_{z}$ indicates the rotation around $x, y$, and $z$ axes. The loads are applied to the side of rail head assuming the train loads, which are composed of the wheel load and the lateral load.

In this study, FEM analyses executed are non-linear elastic analyses using NASTRAN (ver. 10) software (Siemens [8]). The total values of applied loads are divided into 10 steps. The convergence calculation at each step is performed with the quasi-Newton method.

\subsection{Spring coefficients}

The spring coefficients were measured prior to the performance test and incorporated into the FEM model. This study focuses on the rail fastening as shown in Fig. 4. The coefficient of the spring under the rail and the tie plate was measured by applying the compression force from $0 \mathrm{kN}$ to $100 \mathrm{kN}$ to the rail as shown in Fig. 5. The coefficient of the tip spring was measured by applying the vertical force to the rail as shown in Fig. 6. The test procedure was done as follows: The initial displacement of rail was set to $0 \mathrm{~mm}$. The rail was pulled up and the rail pad was extracted from under the rail. The force applied to the rail at this time was defined as Pmax. The force was decreased until $0 \mathrm{kN}$ and was increased until Pmax once again. As a result, the relationship between the force and the displacement was measured and was defined as the coefficient of the tip springs. The force at the time of displacement was decreased until $0 \mathrm{~mm}$ was defined as the initial clamping force. The coefficient of the lateral springs was measured by applying the lateral force from $0 \mathrm{kN}$ to $60 \mathrm{kN}$ to the rail base as shown in Fig. 7. The coefficient of the coil spring was presented by manufacturer. The relationships between the force and the displacement obtained above were approximated by some lines and the coefficient of each spring was determined as shown in Fig. 8. The spring coefficients of the lateral springs and the tip springs are the values per a clip. The initial clamping force was $4 \mathrm{kN}$ per a clip.

\subsection{FEM results}

FEM analyses were carried out in two cases (case A and case B). The wheel loads and lateral loads which apply on the FEM model are shown in Table 1. The design load A is applied to the rail from the gauge corner and the design load B is applied from the field corner alternately. These loads are generally used at the sharp curved track. As FEM results, Fig. 9 shows the distribution of rail head displacement, rail base displacement and rail tilting angle.

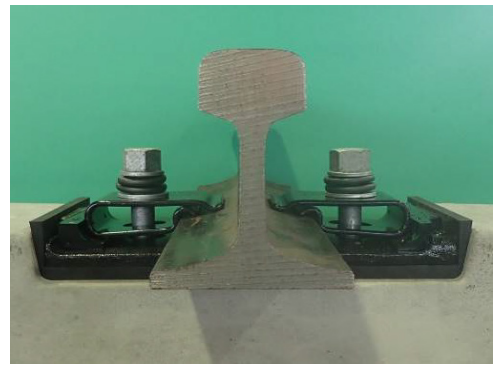

Figure 4: Rail fastening.

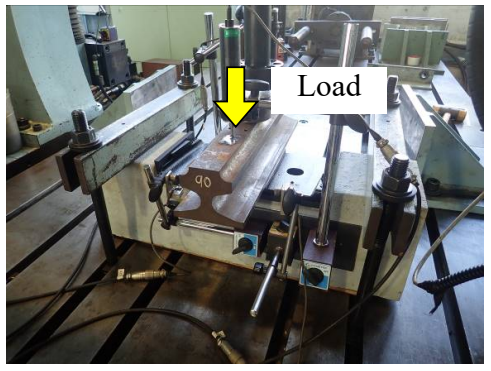

Figure 5: Test for spring under rail and tie plate. 


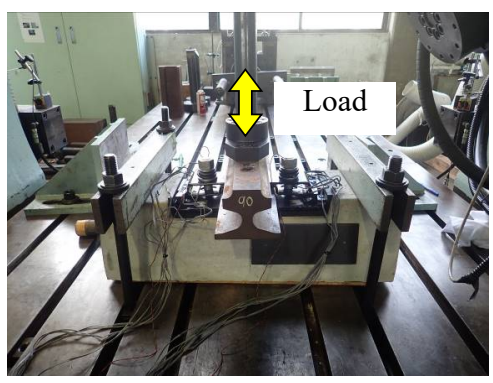

Figure 6: Test for tip spring.

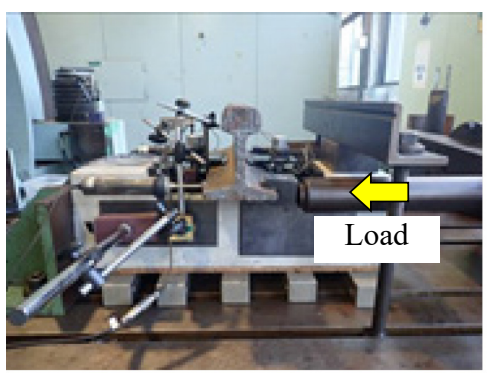

Figure 7: Test for lateral spring.

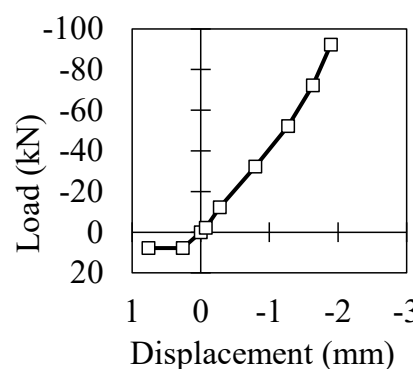

(a)

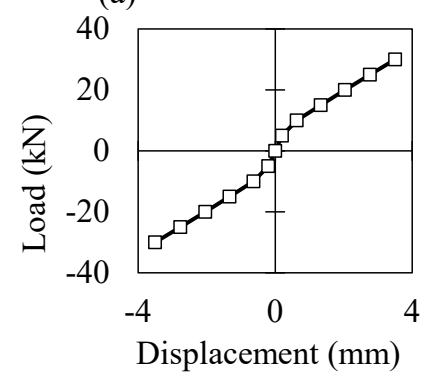

(d)

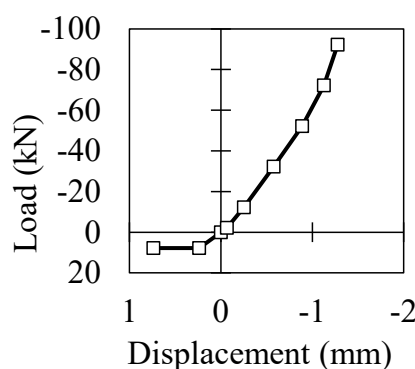

(b)

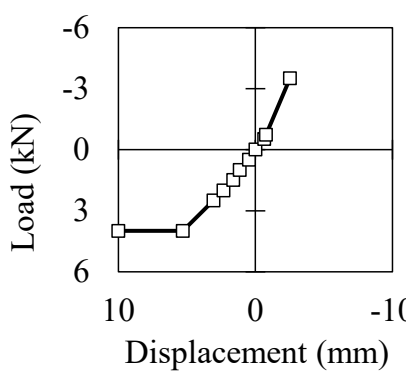

(c)

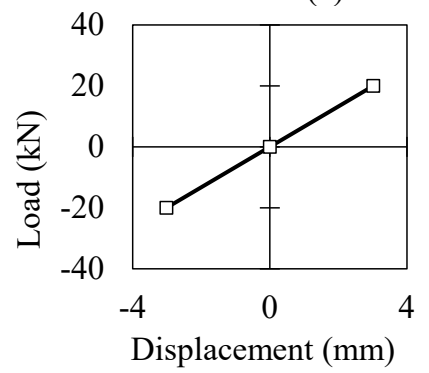

(e)

Figure 8: Spring coefficients of each spring. (a) Spring under rail; (b) Spring under tie plate; (c) Tip spring; (d) Lateral spring; and (e) Coil spring.

Table 1: Wheel load and lateral load (Meter-gauged line, $\mathrm{R}<600 \mathrm{~m}$ ).

\begin{tabular}{|c|c|c|}
\hline Load & Case A (Design load A) & Case B (Design load B) \\
\hline \hline Wheel load $P$ & $98 \mathrm{kN}$ & $86 \mathrm{kN}$ \\
\hline Lateral load $Q$ & $60 \mathrm{kN}$ & $30 \mathrm{kN}$ \\
\hline
\end{tabular}




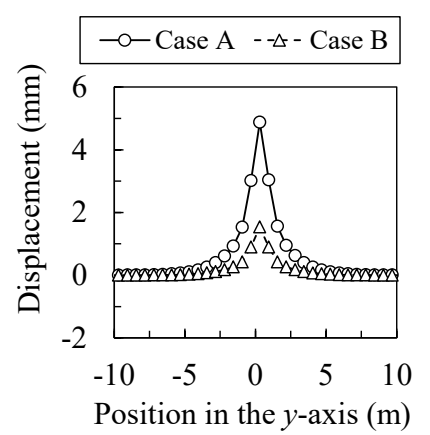

(a)

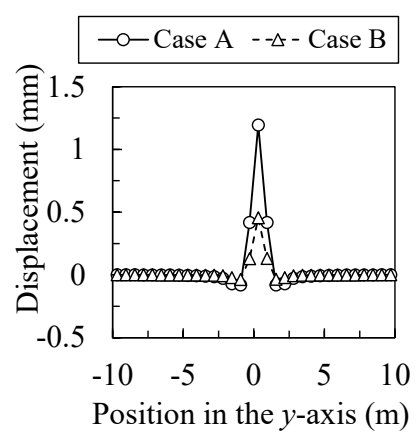

(b)

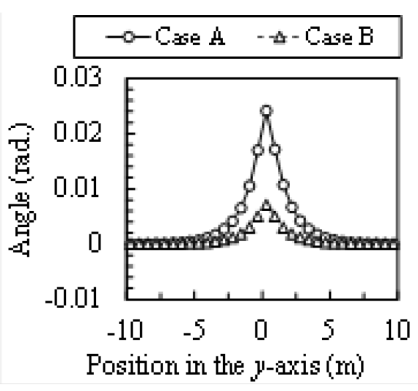

(c)

Figure 9: FEM results of rail displacements and rail tilting angle. (a) Rail head displacement; (b) Rail base displacement; and (c) Rail tilting angle.

On the basis on the FEM results, vertical rail pressure $W$, lateral rail pressure $H$ and rail tilting moment $M$ was calculated by the following equations (wherein each symbol is as described in Fig. 10)

$$
\begin{gathered}
W=\sum_{i=-n}^{n}\left(W_{i}\right)-\left(P_{l}+P_{r}\right), \\
H=R_{l}+R_{r}, \\
M=\sum_{i=1}^{n}\left(W_{i} \cdot b_{i}\right)-\sum_{i=-n}^{-1}\left(W_{i} \cdot b_{i}\right)+\left(P_{l} \cdot d_{l}-P_{r} \cdot d_{r}\right)+\left(R_{l}+R_{r}\right) \cdot c .
\end{gathered}
$$

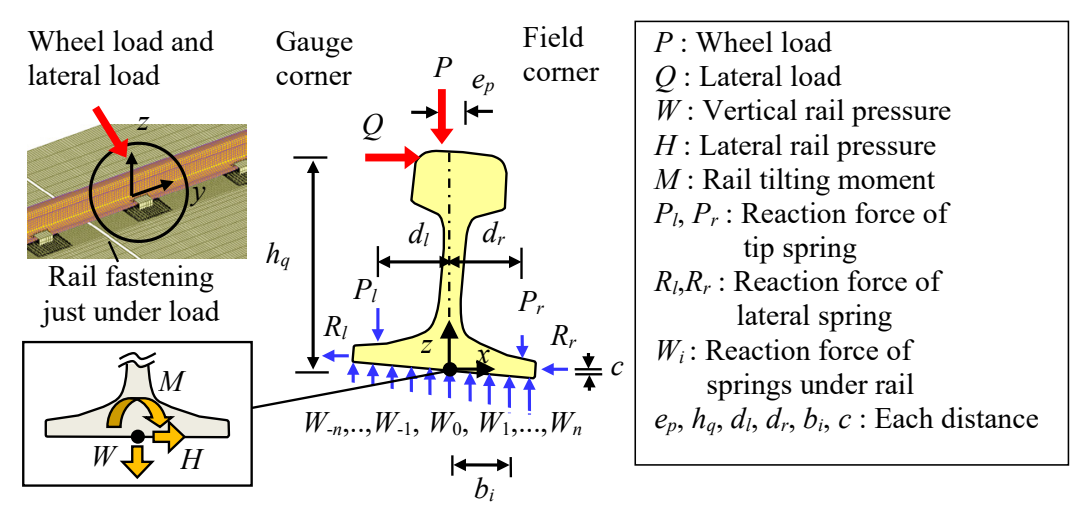

Figure 10: FEM model balanced under wheel load and lateral load.

Fig. 11 shows the distribution of vertical rail pressure, lateral rail pressure and rail tilting moment. Table 2 shows the rail displacements and dispersed load at the point of the load application. 


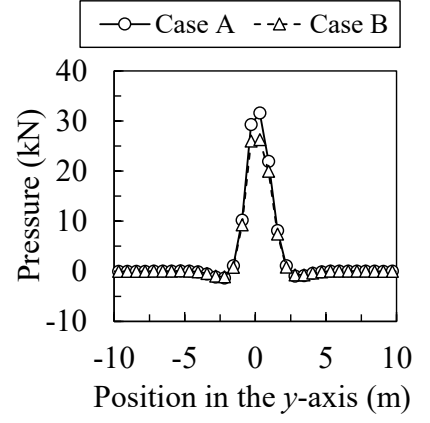

(a)

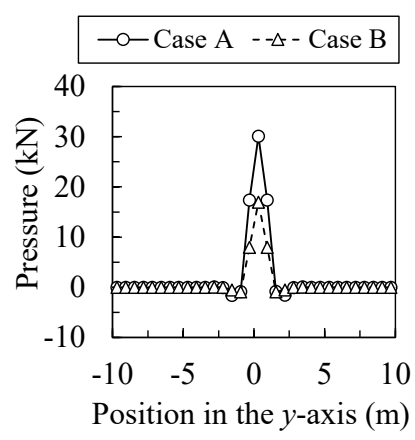

(b)

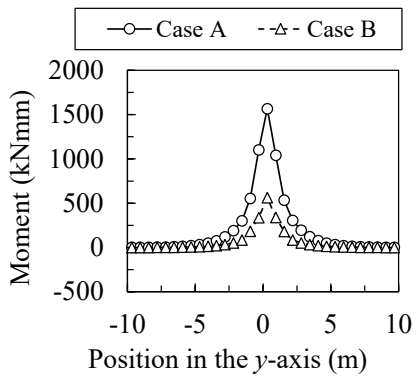

(c)

Figure 11: Dispersed design loads estimated from FEM results. (a) Vertical rail pressure; (b) Lateral rail pressure; and (c) Rail tilting moment.

Table 2: Rail displacements and dispersed loads at the point of the load application.

\begin{tabular}{|c|c|c|c|c|}
\hline \multicolumn{2}{|c|}{ Item } & Unit & Case A & Case B \\
\hline \hline \multirow{3}{*}{ Rail displacements } & Rail head displacement & $\mathrm{mm}$ & 4.88 & 1.54 \\
\cline { 2 - 5 } & Rail base displacement & $\mathrm{mm}$ & 1.2 & 0.45 \\
\cline { 2 - 5 } & Rail tilting angle & $\mathrm{rad}$ & 0.0241 & 0.0071 \\
\hline \multirow{3}{*}{ Dispersed loads } & Vertical rail pressure $W$ & $\mathrm{kN}$ & 31.6 & 26.3 \\
\cline { 2 - 5 } & Lateral rail pressure $H$ & $\mathrm{kN}$ & 30.1 & 17 \\
\cline { 2 - 5 } & Rail tilting moment $M$ & $\mathrm{kNmm}$ & 1567 & 564 \\
\hline
\end{tabular}

\section{CALCULATION OF LOAD CONDITIONS FOR PERFORMANCE TEST}

This section shows the method for determining the loading conditions of the performance test based on the FEM results.

\subsection{Calculation method}

The performance test is performed under bi-axial loading condition in which the loads are applied alternately from the gauge corner and the field corner of test rail as shown in Fig. 12. Test loads $L_{A}$ and $L_{B}$, the angles of load application $\theta_{A}$ and $\theta_{B}$, and the height of load application $h$ are expressed by the following equations

$$
\begin{gathered}
L_{A}=\sqrt{\left(W_{A}-L_{0} \sin \theta_{B}\right)^{2}+\left(H_{A}+L_{0} \cos \theta_{B}\right)^{2}}, \\
L_{B}=\sqrt{\left(W_{B}-L_{0} \sin \theta_{A}\right)^{2}+\left(H_{B}+L_{0} \cos \theta_{A}\right)^{2}}, \\
\theta_{A}=\tan _{-1}\left(\frac{W_{A}-L_{0} \sin \theta_{B}}{H_{A}+L_{0} \cos \theta_{B}}\right),
\end{gathered}
$$




$$
\begin{aligned}
& \theta_{B}=\tan _{-1}\left(\frac{W_{B}-L_{0} \sin \theta_{A}}{H_{B}+L_{0} \cos \theta_{A}}\right), \\
& h=\frac{M_{A}+e\left(W_{A}-2 L_{0} \sin \theta_{B}\right)}{H_{A}}, \\
& h=\frac{M_{B}+e\left(W_{B}-2 L_{0} \sin \theta_{A}\right)}{H_{B}} .
\end{aligned}
$$

Here, $W_{A}, H_{A}$, and $M_{A}$ or $W_{B}, H_{B}$, and $M_{B}$ are vertical rail pressure, lateral rail pressure, and rail tilting moment calculated by eqns (1)-(3) when design load A or B are applied. The subscript A or B means Case A or B. $L_{0}$ is the minimum load applied in the opposite direction to $L_{A}$ or $L_{B}$ and is set at $5 \mathrm{kN}-10 \mathrm{kN}$ in consideration of stability of the test. The detail of the solution of eqns (4)-(9) is described in the paper (Shingo et al. [6]).

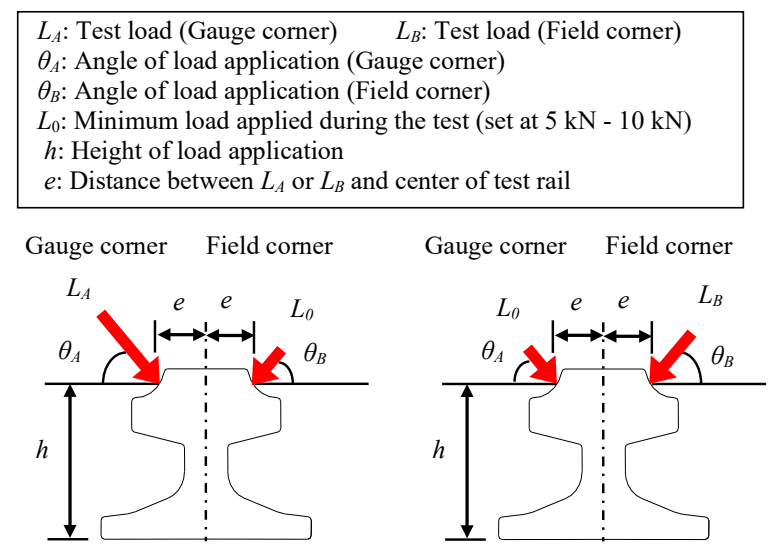

Figure 12: Bi-axial loading condition for performance test. (a) Design load A; and (b) Design load B.

\subsection{Calculation results}

Loading condition of the performance test was calculated on the basis of the FEM results. Substituting the values of vertical rail pressure, lateral rail pressure and rail tilting moment shown in Table 2 into eqns (4)-(9), we calculate test loads $L_{A}$ and $L_{B}$, the angles of load application $\theta_{A}$ and $\theta_{B}$, and the height of load application $h$ as shown in Table 3. $L_{0}$ and $e$ is set at $5 \mathrm{kN}$ and $30 \mathrm{~mm}$.

Table 3: Load condition of performance test.

\begin{tabular}{|c|c|c|c|c|c|c|c|}
\hline Item & $L_{A}$ & $L_{B}$ & $\theta_{A}$ & $\theta_{B}$ & $h$ & $L_{0}$ & $e$ \\
\hline Unit & $\mathrm{kN}$ & $\mathrm{kN}$ & Degrees & Degrees & $\mathrm{mm}$ & $\mathrm{kN}$ & $\mathrm{mm}$ \\
\hline \hline Value & 42.0 & 29.3 & 41.2 & 51.6 & 80 & 5 & 30 \\
\hline
\end{tabular}




\section{PERFORMANCE TEST OF THE RAIL FASTENING}

In order to verify the validity of the calculation of loading condition based on the FEM model, the performance test was carried out. The test result was compared with the FEM results.

\subsection{Test procedure}

Fig. 13 shows the test specimen. A concrete block cut to the length of $700 \mathrm{~mm}$ was set on the testing machine. JIS-50 $\mathrm{kgN}$ test rail (height $80 \mathrm{~mm}$ ) was set on the block and was fastened to the block by the rail fastenings of the floating slab track. Rail clips were fastened by the bolts with $140 \mathrm{Nm}$, the torque specified in the specifications. The block was fastened to the testing machine firmly without elastic layers. Table 4 shows the process of loading. The load condition refers to Table 3. Fig. 14 shows the measuring points of rail displacement. Rail tilting angle was calculated by dividing the difference between the displacement at measuring point 1 and 2 by the distance between two measuring points $(115 \mathrm{~mm})$. Rail base displacement was measured at point 3 . We converted rail head displacement into a value of the top of JIS-50 $\mathrm{kgN}$ rail by multiplying rail tilting angle by a height of JIS-50 kgN rail $(153 \mathrm{~mm})$ and by adding rail base displacement. The direction of lateral displacement from gauge corner to field corner was defined as positive and clockwise rail tilting angle was defined as positive.

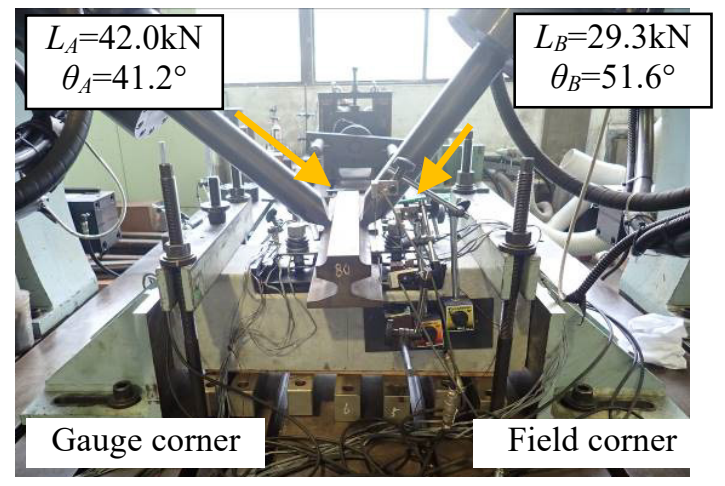

Figure 13: Performance test specimen.

Table 4: Load procedure.

\begin{tabular}{|c|c|}
\hline Load procedure & Test load (kN) \\
\hline \multirow{2}{*}{ Preload } & $L_{A}: 0 \rightarrow 5.0$ \\
\hline & $L_{B}: 0 \rightarrow 5.0$ \\
\hline \multirow{2}{*}{$L_{A}$} & $L_{A}: 5.0 \rightarrow 42.0 \rightarrow 5.0$ \\
\hline & $L_{B}: 5.0($ fixed $)$ \\
\hline \multirow{2}{*}{$L_{B}$} & $L_{A}: 5.0$ (fixed) \\
\hline & $L_{B}: 5.0 \rightarrow 29.3 \rightarrow 5.0$ \\
\hline
\end{tabular}




\section{Gauge corner Field corner}

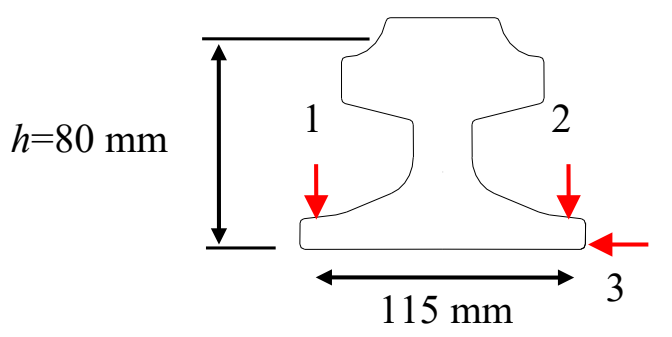

Figure 14: Measuring point of test rail displacement.

\subsection{Test results}

Fig. 15 shows the relationship between the test load, and the rail tilting angle and rail displacement. In Fig. 16, the test results were compared with the FEM results described in Table 2. Regarding rail head displacement, FEM result was in good agreement with test result when $L_{A}$ and $L_{B}$ was applied. As regards rail base displacement, FEM result was 0.6 times of test result when $L_{A}$ was applied and was 0.4 times of test result when $L_{B}$ was applied. As for rail tilting angle, FEM result was 1.4 times of test result when $L_{A}$ was applied and was 1.9 times of test result when $L_{B}$ was applied.

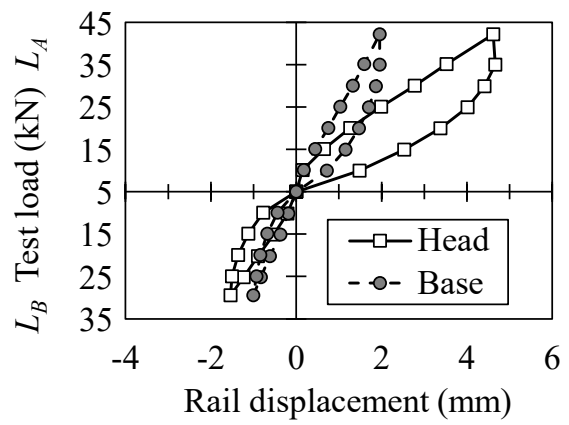

(a)

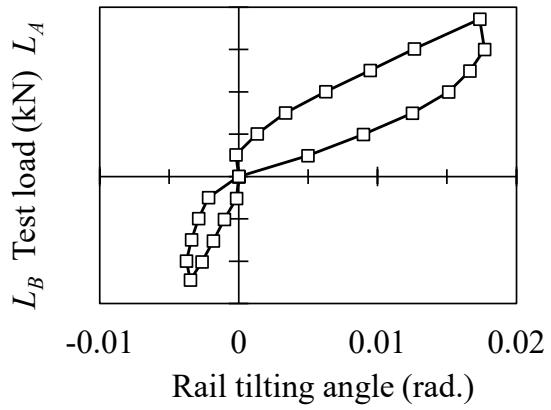

(b)

Figure 15: Rail head and base displacement and rail tilting angle obtained by the performance test. (a) Rail head and base displacement; and (b) Rail tilting angle.

\section{CONCLUSION}

This study examines the calculation method of load conditions for performance test of rail fastenings of a floating slab track. The obtained main results are as follows:

1. A FEM model of a floating slab track is developed to estimate the dispersed forces and the calculation method of load conditions based on the FEM results are proposed.

2. The effectiveness of the calculation method of load conditions was verified by comparing FEM results with test results. 


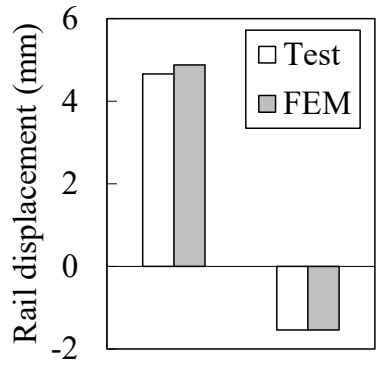

(a)

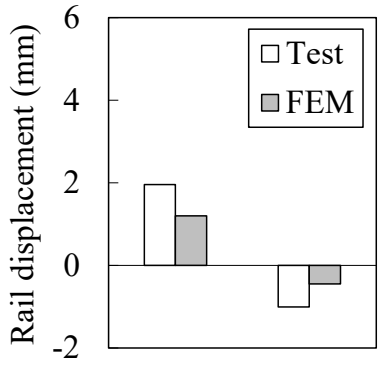

(b)

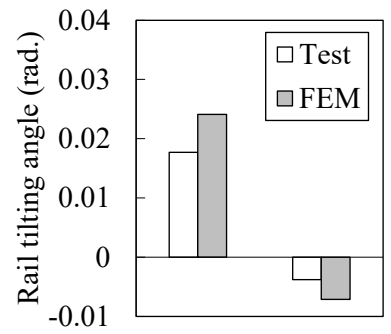

(c)

Figure 16: Comparison between test results and FEM results. (a) Rail head displacement; (b) Rail base displacement; and (c) Rail tilting angle.

From the above results, FEM results were substantially coincident with test results. Therefore, it is concluded that the effectiveness of the calculation method of load conditions for performance test based on the developed FEM model is verified.

The calculation method based on the FEM model can evaluate the performance of rail fastenings of the floating slab track with higher accuracy than before. Therefore the rational design of the rail fastenings can be expected and the further adoption of the floating slab track can be expected. In addition, the proposed method may become the Japanese standard of the performance test for the rail fastenings of the slab track. In recent years, in order to respond to the globalization of the railway business, Japan have participated in the international standard development of the railway track (Katsumi [9]). In particular, international standard for the rail fastenings are now discussed at ISO/ TC269/SC1/WG7. The author will continue efforts to reflect the Japanese ideas in the international standards.

\section{ACKNOWLEDGEMENT}

The author wishes to thank Kita-Osaka Kyuko Railway Co. Ltd. for providing the specimens and supporting the tests.

\section{REFERENCES}

[1] Japan Railway Construction Public Corporation, Construction of Rinkai Line, 2003.

[2] Railway Technical Research Institute, Design Standards for Railway Structures and Commentary (Track Structures), Maruzen, 2012.

[3] Youichi, H., A practical solution for the torsion (tilting) of rail. Journal of Japan Society of Civil Engineering, 210, pp. 33-46, 1973.

[4] Yutaka, S., On the lateral strength of railway track. Railway Technical Research Report, Railway Technical Research Institute, 110, 1960.

[5] Takeshi, Y., Shizuya, U. \& Toshiyuki, K., Relationship between spring coefficient of fastening device and rail overturning angle. Quarterly Reports, Railway Technical Research Institute, 22(4), pp. 153-156, 1981.

[6] Shingo, T., Hiroo, K. \& Tadashi, D., Practical model for rail tilting and its application to performance test of rail fastening system. Journal of JSCE, 7, pp. 1-14, 2019.

[7] Tadashi, D., Shingo, T., Masato, N. \& Hiroo, K., Improving the performance of rail fastening system evaluation. Quarterly Report, Railway Technical Research Institute, 59(3), 2018. 
[8] NX Nastran User's Guide, Siemens PLM software, 2014.

[9] Katsumi, M., Development status of International standards on the rail track and the trend of the related research of RTRI. RTRI Report, 31(12), pp. 1-4, 2017. 